Aus der Prov.-Hebammenlehranstalt in Osnabrück.

(Director Dr. Rissmann.)

\title{
Der Einfluss der Geburtsverletzungen des Introitus vaginae auf das Wochenbett.
}

Von

Dr. W. Timmermann.

Die letzten Jahre brachten uns eine Reihe umfangreicher bacteriologischer Arbeiten über die Aetiologie des Puerperalfiebers, deren Ergebnisse sich aber häufig so unvermittelt gegenüberstehen, dass es dem Praktiker schwer fällt, aus den differirenden Lehren der Kliniker die richtigen Consequenzen für die Praxis zu ziehen ${ }^{1}$ ).

Zu den viel umstrittenen Fragen gehört auch die über die Nothwendigkeit der Scheidendesinfection, und der Praktiker würde, wenn er auch noch so gewissenhaft die gesammte Literatur über dieses Thema zu Rathe zöge, kaum je zu einem abschliessenden Urtheile gelangen. Die einen warnen ihn, bei dem physiologischen Vorgange der Geburt die inneren Genitalien überhaupt zu berühren, die anderen fordern strikte eine Desinfection derselben. Allgemein aber würdigt man die Desinfection der äusseren Geschlechtstheile der Kreissenden kaum einer besonderen Discussion. Und doch sollte man, ehe man überhaupt die Nothwendigkeit einer Scheidendesinfection erörterte, unseres Erachtens sich vorher über eine Desinfection der äusseren Genitalien einigen. Dies wäre vielleicht das neutrale Gebiet, auf dem sich Freunde S. 969 .

1) Bokelmann, Monatsschr. f. Geb. u. Gyn. 1899. Bd. IX. H. 6. 
und Feinde der Scheidendesinfection die Hand reichen könnten. In diesem Punkte könnten auch Aerzte und besonders Hebammen in der Praxis mehr leisten, als im Allgemeinen geschieht und bisher von ihnen auch nur gefordert wird.

Ich möchte also im Folgenden zeigen, dass wir nach theoretischer Erwägung wie praktischer Erfahrung allen Grund haben, der Desinfection der äusseren Genitalien der Kreissenden und Wöchnerin eine höhere Bedeutung zuzuschreiben, als ihr von vielen Aerzten, jedenfalls aber von allen preussischen Hebammen, die naeh dem Lehrbuche handeln, bislang zuerkannt wird.

Glauben doch viele Geburtshelfer, wenn sie die eigenen Hände und Instrumente, vielleicht auch die Scheide der Kreissenden, nach bestem Können desinficiren, der Prophylaxe völlig genügt zu haben und sind, falls die Wöchnerin dennoch fiebert, schnell, vielleicht $\mathrm{zu}$ schnell bereit, sich selbst zu entschuldigen und die Infection als eine unvermeidliche, dem Arzte nicht zur Last fallende, als eine Selbstinfection zu deuten.

Darin aber liegt gerade eine grosse Gefahr, dass man zur Entlastung seines eigenen Gewissens voreilig die Selbstinfection beschuldigt in Fällen, wo man nach genauem Suchen doch noch Fingerzeige findet, die auf eine wohl vermeidbare Ausseninfection hinweisen. "Von aussen kommt die Gefahr", drückt Bumm ${ }^{1}$ ) sich treffend aus; der Satz gilt, man mag über Selbstinfection denken, wie man will, und diese Gefahr droht nicht allein während der Geburt, sondẹn auch in der letzten Zeit der Schwangerschaft und in den ersten Tagen des Wochenbettes. Wir sehen nicht so selten noch in den späteren Tagen des Wochenbettes Fieber auftreten und dürften, wie ich nachher des Genaueren auszuführen gedenke, in vielen Fällen zu der Annahme berechtigt sein, dass die bei der Geburt entstandenen Wunden, namentlich die des Introitus, nachträglich im Wochenbette inficirt seien. Ahlfeld ${ }^{2}$ ) nennt es zwar einen vollständig unlogischen Schluss, eine Untersuchung in der Schwangerschaft für das im Wochenbette entstandene Kindbettfieber verantwortlich zu machen. Wenn aber die untersuchende Hand virulente Keime eingeschleppt hat, so wüsste ich keinen Grund, warum nicht eine Wunde, die später

1) Centralbl. f. Gyn. 1899. No. 21. S. 628.

2) Zeitschr. f. Geb. u. Gyn. XXVII. H. 2. S. 475. 
auf diesem inficirten Gebiete entsteht, ebenfalls inficirt werden sollte, und wäre es auch ein Schnitt mit sterilem Messer. Weshalb desinficiren denn die Chirurgen das Operationsfeld so gründlich, ehe sie überhaupt zum Messer greifen?1)

Die inneren Geburtswege der Kreissenden, die nach Leopold's") Forderung für den Geburtshelfer ein "noli me tangere" sein sollen, dürften auch in den letzten Tagen der Schwangerschaft sehr oft nicht intact geblieben sein. Von anderer Seite ist schon auf die Möglichkeit aufmerksam gemacht worden, dass Keime vor der Geburt durch den Coitus ${ }^{3}$ ), durch Untersuchung seitens der Aerzte, Laien (Gatte, Selbstuntersuchung) ${ }^{4}$ ) in die Vagina hineingebracht sein können. Diese Gefahr liegt auch bei vielen anderen Manipulationen nahe, so bei Einführung von Ringen, Specula, Bougies, Tampons, Mutterrohren. Dass auch Fremdkörper in der Scheide bis zur Geburt liegenbleiben können, beweist der Fall von $\mathrm{Saft}^{\bar{D}}$ ). Auch Braun ${ }^{6}$ ) hat solche öfters bei Kreissenden entfernt, und wie oft mögen sie von denselben vor der Untersuchung entfernt werden!

In allen diesen Fällen ist doch die Möglichkeit einer Einschleppung gegeben, und erst wenn eine genaue Anamnese in dieser Hinsicht negativ bleibt, und dennoch eine innerlich nicht Untersuchte fiebert, kann man meiner $\Lambda$ nsicht nach dem Gedanken an eine Selbstinfection überhaupt nähertreten. Gerade hier aber dürfte auch die sorgfältigste Anamnese uns nicht immer vor Irrthümern schützen, da wir auf unsere intimen Anfragen oft nicht die Wahrheit erfahren werden.

Zu den ätiologischen Momenten für Selbstinfection wird auch die Auffrischung alter gonorrhoischer Processe gerechnet. Nach dem Vorschlage von Olshausen ${ }^{7}$ ), dem sich Bumm ${ }^{8}$ ) und Baumm ${ }^{9}$ ) anschliessen, ist diese Erkrankung überhaupt vom

1) Centralbl. f. Gyn, 1898. No. 44. S. 1210.

2) Dieses Archiv. Bd. 47. S. 582.

3) Das sächsische Hebammenlehrbuch warnt deshalb $\$ 82$, S. 69, vor dem Coitus in der letzten Zeit der Schwangerschaft wegen der Gefahr des Kindbettfiebers.

4) Fehling, Dieses Archiv. Bd. 35. S. 494 u. 503.

5) Ebendas. Bd. 52. S. 607.

6) Centralbl. f. Gyn. 1897. No. 2. S. 54.

7) Centralbl. f. Gyn. 1899. No. 1.

8) Monatsschr. f. Geb. u. Gyn. 1899. Bd. IX. H. 6. S. 958.

9) Centralbl. f. Gyn. 1899. No. 11. S. 290. 
eigentlichen Puerperalfieber zu trennen. Schliessen wir die Gonorrhoe aus, so werden die Grenzen für den Begriff des Wochenbettfiebers wesentlich bestimmter und, insbesondere die der Selbstinfection, nicht unbeträchtlich enger gezogen ${ }^{1}$ ).

Dass ferner der Vorgang der Geburt die directe Ursache für Recidiviren alter, auch nicht gonorrhoischer Eiterherde werden kann, ist zuzugeben. Ob aber das hierdurch enstandene Fieber als Puerperalfieber anzusprechen ist, erscheint uns zweifelhaft. Ich möchte alte Eiterherde, die durch die Geburt mechanisch aufgerüttelt werden, als Complicationen der Geburt bezeichnen und das dadurch bedingte Fieber rom eigentlichen Puerperalfieber scharf trennen ${ }^{2}$ ). Denn die Infection geht in diesen Fällen nicht von den durch die Geburt gesetzten Wunden des Uterus, der Cervix, Vagina oder äusseren Genitalien aus, und das müssen wir von einem Kindbettfieber doch in erster Linie verlangen. Auch wurden die Keime lange vorher in den Körper gebracht, und das nach Monaten entstehende Fieber kommt indirect auf Rechnung der früheren Geburt, Operation etc. Jedenfalls sind mir solche Fälle kein Beweis für Selbstinfection: wenn auch den jetzigen Geburtshelfer nicht die Schuld trifft, so fällt die spätere Infection noch dem früheren Operateur, der früheren Erkrankung zur Last. Die Kreissende inficirt sich nicht, wird auch nicht von mir inficirt, sondern ist es bereits von einer früheren Erkrankung her. Es dürfte deshalb logischer sein, diese für das Fieber im Wochenbette verantwortlich zu machen und die Deutung als Selbstinfection zu rermeiden.

Dieses Wort erklärt auch jene Fälle von Fieber bei innerlich nicht berührten Wöchnerinnen meines Erachtens nicht genügend, in denen Wunden der äusseren Genitalien die Möglichkeit einer Ausseninfection bieten. Liegt es da nicht viel näher, diese als Eingangspforte aufzufassen? Warum sollen wir uns auf das dunkle Gebiet der Selbstinfection verirren, wenn uns auf einer anderen Seite mehr Licht winkt? Die schmutzigen Beläge sprechen doch oft deutlich genug für eine Ausseninfection, und wenn gar die Section die Streptokokkeninvasion, ausgehend von einem Ulcus des Labium, als Todesursache nachweist, dürfte es

1) Ebendas. No. 6. S. 162.

2) Bumm, Frommel's Jahresber. 1898. S. 787. (Unzugänglich.) 
näher liegen, den Schuldigen draussen zu suchen, auch wenn die Frau nicht untersucht ist.

Wir werden später auf die Bedeutung der Introitusverletzungen als Infectionsquellen noch näher eingehen. Zunächst aber möchte ich unter Berücksichtigung der bisher erörterten Gesichtspunkte die von Ahlfeld ${ }^{1}$ ) zusammengestellten ,Todesfälle an puerperaler Sepsis ohne vorausgegangene Untersuchung" etwas genauer betrachten. Ich erwähne bei jedem Falle den Grund, weshalb die Annahme einer Ausseninfection uns vielleicht ebenso berechtigt erscheint, wie die einer Selbstinfection (Ahlfeld) ${ }^{2}$ ).

Fall 1. Wunden der äusseren Genitalien und Scheide missfarbig.

Fall 2. Greift mit schmutzigen Händen an den Genitalien herum.

Fall 3. -

Fall 4. Am Tage vor der Geburt angeblich Schüttelfrost. 5 Min. p. p. 38,7. An der Commissura post. stark belegtes Ulcus.

Fall 5. 4 Tage vor der Geburt in der Anstalt eine Untersuchung.

Fall 6. 3 Tage vor der Geburt letzte interne Untersuchung.

Fall 7-15. Bei jeder Kreissenden ante part. reichliche vaginale Ausspülungen (Lachmanski verwirft deshalb die Ausspülungen). Ausserdem :

Fall 8, 8 St. ante part. Schüttelfrost. Empyem. Dammriss 2. Grades

Fall 9. Am 6. Tage aufgestanden. Darauf Fieber. Vgl. Fall 18.

Fall 10-13. Endemie von Puerperalfieber; Entbindungen am 18., 17.-18., 28. Dez. Lachmanski fübrt die Infection auf Uebertragung zurück. Unwahrscheinliche Häufung von Todesfällen an Selbstinfection.

Fall 14. Nicht Puerperal-Infection. Exitus nach 3 fieberfreien Tagen an Embolie der Art. pulm. dextr.

Fall 15. Nicht Puerperal-Infection. Retroperitonealer Abscess älteren Datums.

Fall 16. 4 Tage a. p. Ring eingelegt.

Fall 17. Oedem der äusseren Genitalien. Streptococeeninvasion ausgehend von einem Ulcus der Schamlippe.

Fall 18. Am 4. Tage setzte sich die widerspenstige Wöchnerin wiederholt auf, darauf Fieber. Leopold (S. 70) glaubt, dass dadurch Wunden am Collum aufgerissen seien und in ein schon in der Schwangerschaft inficirtes (Ausseninfection!) Vaginalsekret eingetaucht hätten.

Fall 19. Eitrige Salpingitis rechts, die nach Leopold's Annahme schon in der Schwangerschaft bestand. Auch sei nicht auszuschliessen, dass in den ersten 18 Stunden der Geburt draussen eine Selbstuntersuchung stattgefunden habe. Kleiner belegter Schleimhautriss hinter dem Frenulum.

1) Zeitschr. f. Geb. n. Gyn. XL. H. 3. S. 414.

2) Im Original konnte ich nur die Fälle 2-4, 7-15, 18-21 nachlesen. Bei den übrigen eitire ich Ahlfeld's eigene Angaben. 
Fall 20. Leopold nimmt an, dass die Frau 11 Tage a. p. vom Arzte, der zu gleicher Zeit täglich ein Panaritium verband und trotzdem die Schwangere untersuchte, inficirt sei. Auch litt die Wöchnerin an eiteriger Angina, also vielleicht Infection durch den eigenen Finger mit Anginasekret.

Fall 21. -

Fall 22. Peritonitis, ausgehend von alten Eiterherden, die sich an eine Ovariotomie anschlossen.

Fall 23. Gonorrboe des Mannes erwiesen.

Die Mehrzahl dieser schweren Infectionsfälle, die Ahlfeld auf Selbstinfection zurückführt, könnte man also theils auf andere Weise ungezwungen erklären, theils aber überhaupt vom Puerperalfieber ausschliessen. Gestand doch selbst Kaltenbach ${ }^{1}$ ) den Gegnern der Selbstinfection zu, dass alle derartigen Erkrankungen auch durch Ausseninfection entstanden sein könnten.

Wie ich schon oben bemerkte, könnte vielleicht ein Theil der Selbstinfectionsfälle auf eine Infection der Wunden an den äusseren Genitalien zurückgeführt werden, und wir wären dann doch zu der wahrscheinlicheren Annahme einer Ausseninfection gezwungen. Diese äusseren Verletzungen sind, glaube ich, in ihrer Bedeutung für. Fieber im Wochenbette nicht immer genügend berücksichtigt worden.

Einzelne Autoren beachten in den Morbiditätsstatistiken zwar die Dammrisse; aber jene zahllosen kleinen Verletzungen des Scheideneinganges finde ich in den grossen Berichten kaum beachtet. Der Einzige, der sich mit ihnen sehr eingehend beschäftigt, ihren Einfluss auf's Wochenbett genau nachweist, ist Szabó. Seine beiden Arbeiten stammen aus dem Jahre $1884^{2}$ ) und $1889^{\circ}$ ), und 10 Jahre sind verflossen, ohne dass einer der Autoren, die Jahr aus, Jahr ein in umfangreichen Arbeiten aus Hunderten und Tausenden von Geburten statistische Gesetze ableiteten, Szabó's Erfahrungen verwerthet, seine Schlüsse geprüft hätte.

Dieses Schweigen ist um so weniger erklärlich, als beide Arbeiten ein Thema sehr genau behandeln, das vorher wenig beachtet war, von Szabó aber unter vielseitiger Beleuchtung des Stoffes in's helle Licht gerückt wurde. Es dürfte daher wohl an

1) Dieses Archiv. Bd. 35. S. 491.

2) Klinische Mittheilungen aus der I. geb.-gyn. Universitäts-Klinil in Budapest, herausgegeben von Kézmárszky. Stuttgart 1884. Verlag v. Enke. S. 120 .

3) Dieses Archiv. Bd. 36. S. 77. 
der Zeit sein, sich mit diesem vernachlässigten Thema etwas genauer zu beschäftigen.

Dass Verletzungen des Scheideneinganges sebr häufig sind, wird allgemein angenommen. Schröder (Lehrb.), dem sich Spiegelberg (Lehrb.) anschliesst, fand die kleinen Schleimbantrisse bei $\mathrm{I} P$. stets, bei $M$. P. sehr häufig. Winckel ${ }^{1}$ ) nimmt an, dass fast bei jeder Entbindung Schleimhautrisse eintreten. So. notirt Schröder ${ }^{2}$ ) in 63 pCt. der Geburten Verletzungen der äusseren Genitalien, Winckel2) in 96 pCt., Szabóa) findet 48 pCt. (für M. P. 27, für I. P. 77 pCt.), später ${ }^{3}$ ) 39 pCt. Ich selbst beobachtete bei 48 von 50 , also bei 96 pCt. der Wöehnerinnen Risse. Diese grossen Schwankungen erklären sich wohl durch die individuelle Auffassung der Aerzte, die kleinere Verletzungen als zu unbedeutend oft gar nicht verzeichneten.

Dabei ist es nicht die hintere Commissur allein, die einreisst, sondern oft ist das Frenulum intact, aber die Fossa navicularis weist kleine Risse auf. Häufig fand ich auch den Angaben Schröder's gemäss kleine Risse an der Innenfläche der kleinen Jabien, nicht so oft dagegen solche seitlich von der Urethra. So fanden sich auch nach Szabó 56 pCt. der Wunden hinten, 39 pCt. seitlich und nur 5 pCt. vorn.

Gewiss sind diese Verletzungen oft klein, ja häufig erst bei genauem Zusehen zu entdecken. Aber sie haben, so geringfügig sie sein mögen, als Infectionsherde immer ihre Bedeutung (Spiegelberg, Lehrb.). Ob das normale Scheiden- und Uterussecret einer Schwangeren oder Wöchnerin solche Wunden inficiren kann, ist eine Frage, über die sich die berufensten Forscher noch nicht einigen konnten, aber wohl Niemand wird bestreiten, dass die Bakterien der Vulva diese Rolle spielen können. Denn an den äusseren Genitalien sind Keime (Streptococcen, Bact. coli) in reichlicher Menge gefunden ${ }^{4}$. Und hier sollten sie ein beschauliches saprophytisches Dasein führen? Angenommen, sie thäten es: wer will sie hindern, bei passender Gelegenheit ibre guten Vorsätze zu vergessen und uns ihre wahre Natur zu zeigen? Wie die Keime

1) Pathol. u. Ther. d. Wochenb. III. Aufl, 1878. S. 179.

2) Szabo's erste Arbeit. S. 121.

3) 2. Arb. S. 98 .

4) Goenner, Centralbl. f. Gyn. 1899. No. 21. S. 630. - Krönig, Ebendas. 1899. No. 23. S. 679. - Ziegenspeck, Dieses Archiv. Bd. 35. S. 502 . 
an Virulenz verlieren können, so können sie doch erwiesenermaassen unter günstigeren Existenzbedingungen - und solche sind ihnen an den Genitalien der Wöchnerin doch wahrhaftig geboten - auch wieder ihre volle Wirksamkeit entfalten. Das hat das Bact. coli oft genug bewiesen und dadurch seinen guten Ruf als friedlicher Darmbewohner endgültig verscherzt. Auch fand Krönig ${ }^{1}$ ) bei jauchiger Peritonitis 2 mal nur saprogene Bakterien.

Ich kann mich daher der Ansicht Baumm's'), der den Schmutz der äusseren Genitalien zum unschuldigen alltäglichen Hausschmutze rechnet, nicht anschliessen, kann auch der ,überall zweckmässig waltenden Natur den Vorwurf nicht ersparen, dass sie den Feind vors offene Thor postirt."

Diesem Feinde sind in erster Linie die Wunden des Introitus preisgegeben, für welche die Verhältnisse die denkbar ungünstigsten sind. Zuerst ist das Gebiet, auf dem der Riss entsteht, meist reichlich mit Keimen bedeckt, um so mehr natürlich, je geringer die Sorgfalt ist, mit der man ante partum die Reinigung (bez. Desinfektion) vornimmt. Auch wenn die Theile im Beginne der Geburt wirklich keimfrei gemacht sein sollten, bleiben sie es im weiteren Verlaufe derselben wohl nie. Bei der Untersuchung, beim Dammschutz, bei der Berührung mit Wäschetheilen, Unterlagen, durch das Kind, in der Nachgeburtsperiode, beim Stuhlgang werden immer wieder Keime an die äusseren Genitalien herangebracht. So hat auch Gebhard ${ }^{3}$ ) das Bact. coli intra partum am Damme nachgewiesen. Noch schwieriger als bei der Geburt lassen sich die äusseren Geschlechtstheile im Wochenbette sauber halten. Dass aber Introitusrisse auch im Wochenbette für Infection höchst empfänglich sind, beweist ein Fall ${ }^{4}$, in dem ein kleiner Riss mit Diphtherie und später, noch am 15. Tage des Wochenbettes, mit Erysipel inficirt wurde.

Unter diesen ungünstigen Bedingungen wird sehr oft eine Infection der äusseren Verletzungen eintreten müssen, die sich meist dureh charakteristische Beläge verräth. Winckel5) sah, dass von

1) Monatsschr. f. Geb. u. Gyn. 1899. Bd. IX. H. 6. S. 961.

2) Dieses Archiv. Bd. 52. S. 624 .

3) Zeitschrift f. Geb. u. Gyn. Bd. 37. H. 1. S. 135.

4) Burckhardt, Zur Aetiologie des Puerperalfiebers. Der Frauenarzt. I. Jahrg. S. 9-13, 68-72.

5) Pathologie und Therapie des Wochenbettes. III. Aufl. 1878. S. 178. 
164 Fissuren der Labien 104, d. i. 63 pCt., ulcerirten. In diesen Belägen finden wir denn auch die verschiedensten Bakterien, mit denen wir uns in einer späteren Arbeit des Genaueren beschäftigen werden.

In solchen Fällen sprechen die Beläge, das Oedem, die Infiltration deutlich genug; in anderen aber könnte uns die makroskopische Reinheit der Wunden, ihr gutes Aussehen und baldige Verheilung zur Annahme verführen, sie seien nicht die Eingangspforten für Bacterien gewesen. Wenn die Wunden noch so gut aussehen, ihr Grund röthlich, ihre Umgebung nicht geschwollen ist, so möchte ich, entgegen $\mathrm{Bumm}{ }^{1}$ ), doch nicht unbedingt diesen Unschuldsbetheuerungen Glauben schenken. Nimmt doch auch Widal'2) an, dass die Bacterien ohne örtliche Entzündungs- und Eiterungserscheinungen in die Blutbahn eindringen und dann die reine, meist tödtliche Septicämie hervorrufen können. Diese Annahme, dass Bakterien, ohne an der Eingangspforte sichtbare Veränderungen hervorzurufen, trotzdem an entfernten Orten ihre volle Wirksamkeit entfalten, ja den Gesammtorganismus inficiren können; hat nichts Gezwungenes oder Unwissenschaftliches, und meines Erachtens darf sie der Geburtshelfer ebensogut annehmen, wie sie in der Chirurgie und inneren Medicin von Niemand mehr bestritten wird $\left.{ }^{3}\right)$.

Wir sehen, dass die Wunden der äusseren Genitalien der Infection in hohem Maasse zugänglich sind, und müssen nun weiter fragen: Hat die Infection dieser Wunden einen Einfluss auf das Wochenbett?

Schröder (Lehrb. S. 628) sagt: „Fieber ist mit dem Auftreten von Puerperalgeschwüren fast immer verbunden, da der entzündliche Process sich auf das umgebende Bindegewebe fortsetzt; dass sie selbst aber an dieser Temperaturerhöhung unschuldig sind; beweist die bei sehr ausgebreiteten, dickbelegten Geschwüren oft sehr niedrige Temperatur."

Allerdings macht nicht jede örtliche Entzündung und Eiterung Fieber, aber wenn es eintritt, so giebt man, wenn keine andere

1) Centralbl. f. Gyn. 1899. No. 6. S. 164.

2) Dieses Archiv: Bd. 57. S. 37.

3) Leopold, Geb. und Gyn. II. Bd. der Arb. aus der Königl. Frauenkl. Dresden. S. 66. Leipzig 1895. 
Lrsache nachzuweisen ist, doch immer jenem krankhaften Processe die Schuld; in den Fällen von Geschwüren ohne Fieber ist eben die Infection localisirt geblieben, und die fiebererregenden Producte haben nicht den $W e g$ in die Blut- oder Lymphbahnen gefunden.

An einer anderen Stelle (609) sagt Schröder: „In der Mehrzahl der Fälle (d. h. häufiger als dureh die Placentarstelle und Cervixrisse) wird die Jnfection vermittelt durch die kleinen Schleimhautrisse, die sich bei jeder I. P. und auch bei der grossen Mehrzahl der I. P. beim Durchschneiden des Kopfes in Scheideneingange bilden.

Aehnlich äussert sich Fischel1), welcher glaubt, dass Puerperalgeschwüre viel häufiger der Sitz der primären Infection seien als das Endometrium, und hier einen wesentlichen Angriffspunkt bei der puerperalen Sepsis sieht.

Für Winckel2), "unterliegt es keinem Zweifel, dass die Verletzungen des Scheideneinganges fast jmmer den ersten und wichtigsten Ort der Einimpfung des Giftes abgeben."

Döderlein ${ }^{3}$ ) sagt: "Staphylokokken in der Scheide und ein Uleus puerperale machen Fieber bei Keimfreiheit des Uterus."

Leopold ${ }^{4}$ : Diplokokken und Staphylokokken in Genitalgeschwüren bewirken selbst bei frühzeitiger Behandlung höhere und längere Steigerung von Temperatur und Puls (Streptokokken berücksichtigt er [No. 26] besonders)."

Anderer Ansicht ist Ahlfeld ${ }^{5}$ ): "Ein grosser Theil dieser Geschwüre mit gelbem Belag stösst sich ab, ohne ein einziges Mal Fieber zu veranlassen, während in den übrigen Fällen das Fieber cine kaum nenneuswerthe Höhe erreicht. Wir verlegen die Bildung der infectiösen Stoffe hauptsächlich in den Uterus.... Erst in zweiter Linie bildet sich das Gift auf der Oberfläche der Wunde selbst durch Zerfall und Stagnation. Alle übrigen Formen der Infection, also Impfinfection durch Finger und Instrumente u. s. w., halten wir für weit seltener." --

1) Centralbl. f. Gyn. 1882 . S. 692 .

2) 1. c. S. 179 .

3) Dieses Archiv. Bd. 35. S. 502 .

4) Geb. und Gyn. II. Bd. der Arb. aus der Königl. Frauenkl. Dresden 1895. S. 70. No. 22.

5) Berichte und Arbeiten. I. S. 214. 
Suchen wir uns nun ein Urtheil zu bilden aus den Zahlen! Zunächst berücksichtige ich allein die Dammrisse, denn ausser Szabó würdigt Niemand die sonstigen Introitusrisse der Aufnahme in eine Morbiditaitsstatistik.

Tch vergleiche hier die Morbidität von Wöchnerinnen ohne Dammrisse mit der von Wöchnerinnen mit Dammrissen. Dies ist, wenn man den Einfluss der letzteren auf das Wochenbett erkennen will, richtiger als dass man, wie Ahlfeld es thut, die Geburten mit Dammrissen der Gesammtzahl (d. h. inel. Dammrisse) gegenüberstellt.

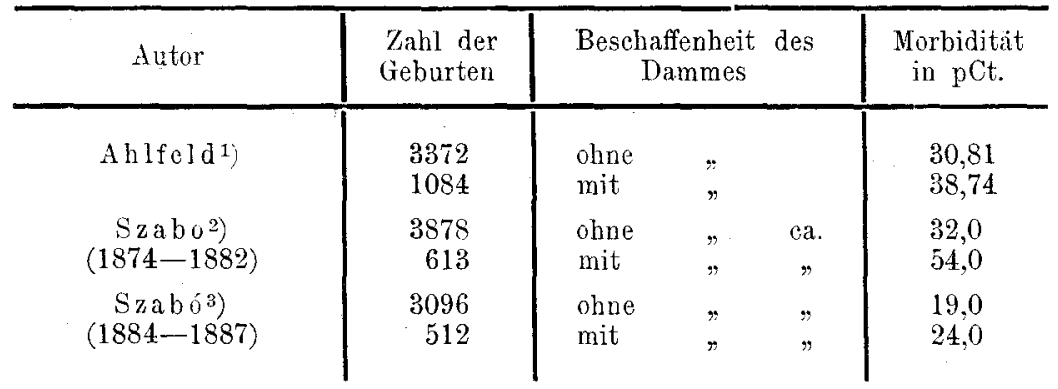

Die geringste Differenz beträgt also 5 pCt. und ist wohl nur dadurch erreicht, dass Szabó nach den schlechten Erfahrungen der früheren Jahre den Wunden der äusseren Genitalien seine ganz besondere Sorgfalt zuwandte. Uebrigens ist der relative Unterschied zwischen Ahlfeld's Resultaten fast genau der gleiche wie zwischen Szabó's zweiten Angaben.

Ahlfeld kommt nach seinem Resultate zu den Schlusse, dass Dammverletzungen in Anstalten, in denen sie unter antiseptischen Maassregeln alsbald nach der Geburt geschlossen werden, selten zu Wochenbettserkrankungen führen, und will solche auf andere Geburtscomplicationen zurückführen. Hier macht er in erster Linie die Operationen verantwortlich. Ahlfeld giebt an, dass bei den 1084 Dammrissen mit 420 fieberhaften Wochenbetten 93 operative Geburten mit 48 fieberhaften Wochenbetten waren. Rechnen wir diese ab, so bleiben für 991 spontane Geburten mit Dammrissen doch noch 372, d. h. 37,54 pCt.

1) Zeitschrift. Bd. 41. Heft 1. S. 7. -- Episiotomien, welche die gleiche Morbidität gaben, sind hier eingeschlossen.

2) Erste Abeit. S. 134 .

3) Zweite Arbeit. S. 98. 
fieberhafte Wochenbetten. Leider fehlt zum Vergleiche die Morbidität spontaner Geburten ohne Dammrisse.

Ferner hebt Ahlfeld hervor, dass die Dammwunde nur in 3,33 pCt. der 420 Dammrisse mit Sicherheit als die Ursache des Fiebers erkannt wurde. Mag auch makroskopisch die Wunde in den übrigen Fällen unschuldig ausgesehen haben, so müssen wir nach den Resultaten der anderen Autoren dennoch den Rissen die Schuld am Fieber geben. Ausserdem steht obige Angabe Ahlfeld's im Widerspruche mit der Häufigkeit der Ulcera puerp. Denn wenn ein Riss ulcerirt, macht er meistens Fieber, und dass weit mehr als 3,33 pCt. der Dammrisse vilceriren, dürfen wir mit der Mehrzahl der Autoren wohl als gewiss annehmen (cf. die oben citirte Angabe Winckel's). Auch dürfte sich, wenn Dammwunden ohne Bedeutung wären, nicht die von Ahlfeld festgestellte, mit ihrer Grösse gesetzmässig steigende Morbidität finden.

Wenn wir einmal die Gefahren des Dammrisses erkannt haben, verdienen auch die übrigen Wunden der äusseren Genitalien unser Vertrauen nicht mehr. Ahlfeld selbst führt den Beweis, dass die Prognose für Dammrisse und Episiotomien fast genau die gleiche ist. $\mathrm{Szabo}^{1}$ ) weist nach, dass, wo Episiotomiewunde neben einem Dammrisse besteht, die Morbidität schlechter ist als bei Dammrissen allein. Beiden aber schenkt der Geburtshelfer eine genaue Beachtung, beide näht man, beiden lässt man eine möglichst sorgfältige Reinigung und Schonung angedeihen, und trotzdem verschlechtern sie die Prognose nicht unbeträchtlich!

Da dürften wir uns, meine ich, gar nicht wundern, wenn sonstige Risse der äusseren Genitalien sich ebenfalls berechtigt glaubten, die Morbidität zu steigern. Denn im Vergleich zu der sorgfältigen Beachtung, deren sich die Dammrisse erfreuen, ist die Behandlung jener Wunden oft recht stiefmütterlich. Während der Geburtshelfer in jedem Falle sich von dem Zustande des Dammes zu überzeugen pflegt, hat er für die äusseren Genitalien im Uebrigen kaum einen Blick übrig und würdigt die Wunden dort erst dann seiner ganzen Aufmerksamkeit, wenn ihm eine unbequeme Blutung Nadel und Faden in die Hand drückt.

Sehen wir nun, welchen Einfluss Introitusverletzungen aufs Wochenbett ausüben!

1) Erste Arbeit. S. 144. 
Nach Ahlfeld ${ }^{1}$ ) berechne ich für:

608 Geb. mit genähten Verletzungen 41,5 pCt. Morb.,

1505 " ohne soche " 26,2 "

Diese genäbten Verletzungen werden allerdings zum grössten Theile Dammrisse gewesen sein. Wunden der äusseren Genitalien allein, also excl. Dammrisse berücksichtigt Szabó ${ }^{2}$ ). Von:

891 Wöchnerinnen mit Introitusverletzungen excl.

Dammrisse fieberten . . . . . . . $29,63 \mathrm{pCt}$.

2205 Wöchnerinnen ohne Verletzungen nur. . . 14,79"

Dasselbe Verhältniss findet er bei alleiniger Berücksichtigung der Erstgebärenden. Von:

751 Erstgebärenden mit Verletzungen der äusseren

Genitalien fieberten . . . . . . $28,50 \mathrm{pCt}$.

437 Erstgebärenden ohne solche nur . . . 14,88"

Wunden der äusseren Genitalien steigern also die Morbidität auf das Doppelte.

In seiner ersten Arbeit ${ }^{3}$ ) sucht Szabó den Einfluss von schweren Quetschwunden der äusseren Genitalien auf das Wochenbett nachzuweisen. Von:

825 Wöchnerinnen mit schweren Quetschwunden

der äusseren Genitalien excl. Dammrisse fieberten . . . . . . . . $50,66 \mathrm{pCt}$.

3053 Wöchnerinnen ohne solche fieberten nur ca. 26 "

Wenn diese Zahlen noch nicht deutlich genug sprechen sollten, so wollen wir auch noch die Mortalität ${ }^{4}$ ) vergleichen. Von:

1438 Wöchnerinnen mit Verletzungen der äusseren

Genitalien starben an Sepsis. . . . . 2,85 pCt.

3053 Wöchnerinnen ohne solche starben an Sepsis 0,82 "

Auch hier eine gewaltige Steigerung, die ja auch andere Ursachen haben mag, aber grösstentheils doch wohl eben durch die Verletzungen bedingtist. SehrähnlicheResultate berechnete Hecker ${ }^{5}$ ) für München, nämlich auf 1063 Frauen mit Dammrissen 2,7 pCt. Mortalität!

Betrachten wir mit Szabó die Morbidität bei Verletzungen der äusseren Genitalien von einem anderen Gesichtspunkte.

1) Zeitschrift f. Geb. und Gyn. Bd. 27. Heft 2. S. 482 u. 469.

2) Zweite Arbeit. S. 98 u. 100.

3) S. 134.

4) S. 134 u. 159 .

5) Dieses Archiv. Bd. XX. S. 380 . 
Es hatten von:

1561 fiebernden Wöchnerinnen. . . $48,17 \mathrm{pCt}$.

109 Wöchnerinnen mit parametritischem Exsudat . . . . 46,78

66 an Sepsis verstorbenen Wöchnerinnen 62 Verletzun-
gen an den äusseren Genitalien.

Zum Ueberfluss. wollen wir uns nun noch die Rolle ansehen, die das Ulcus puerperale in der Morbiditätsstatistik spielt1).

Aus genitaler Ursache fieberten ron 4491 Wöchnerinnen 25 pCt., darunter war Uleus puerperale die Ursache bei 459 , also $10,2 \mathrm{pCt}$.

Aehnliche Zahlen erhält Szabó in seiner späteren Arbeit $\left.{ }^{2}\right)$ :

Aus genitaler Ursache fieberten von 3608 Wöchnerinnen 7,67 pCt., darunter war Ulcus puerperale die Ursache bei 105, also $2,91 \mathrm{pCt}$.

Demnach war das Fieber der Wöchnerinnen, soweit eine genitale Ursache vorlag, in fast der Hälfte der Fälle durch ein Ulcus puerperale bedingt.

Allerdings ist zuzugeben, dass eine strenge Sonderung der Fiebertälle nach der Aetiologie schwer durchzuführen ist, dass ferner verschiedene Ursachen in demselben Falle das Fieber erklären können; so wird sich in den Zahlen mehr oder weniger der subjective Standpunkt des Autors wiederspiegeln. Aber von wem auch die Resultate stammen mögen, im Princip sind sie die gleichen: ein langes Sündenregister für die Wunden des Introitus.

Die Verletzungen der äusseren Genitalien sind also recht häufig die Eingangspforte für Bacterien, welche sich an den äusseren Genitalien aufhalten. Diese Keime der Vulva können aber unter gewissen Bedingungen auch für die Wunden der inneren Genitalien verhängnissvoll werden, sie können bei allen inneren Eingriffen höhergeschleppt werden. Die Gefahr droht besonders, wenn wir genöthigt sind, mit der ganzen Hand, ja bis zum Ellenbogen einzugehen. Immer wieder rollen sich die kleinen, die grossen Labien ein, legen sich dicht dem passirenden Theile an, der bei weiterem Vordringen in die Scheide und womöglich ins Cavum uteri gelangt. Wie hier die Hand, so übernimmt die Zange, der

1) Szabó. Erste Abeit. S. 146.

2) S. 96 und 97 . 
Gazestreifen etc. den Transport. Dieses Aufschleppen von Keimen, abgesehen von anderen Momenten, steigert fraglos die Morbidität bei operativen Geburten nicht unbeträchtlich. Besonders ungünstig liegen die Verhältnisse dann, wenn man die Schamhaare nicht sorgfältig gekürzt hat, die auch durch eine gründliche Reinigung nicht keimfrei gemacht werden könmen und oft so lang sind, dass sie bei der Untersuchung hoch in die Scheide, selbst an die Cervix gelangen können. Dass auch sterile Gaze bei der Einführung in den Uterus das Bacterium coli vom Damme mitnehmen und tödtlich inficiren kann, beweist der Fall aus der Baseler Klinik ${ }^{1}$ ).

Solche Erfahrungen sollten doch zur Vorsicht mahnen und lassen eine von Heymann²) kürzlich empfohlene, im WöchnerinnenAsyl zu Mannheim (Mermann) geübte Methode zur Einleitung der künstlichen Frühgeburt recht bedenklich erscheinen. Mermann lässt nach Desinfection der Hände und Seifenwaschung der äusseren Genitalien die Bougie ohne Benutzung eines Speculums, allein unter Leitung eines eingeführten Fingers, in den Uterus bringen. Die scheinbar so einfache Aufgabe, "die sterile Bougie in den Uterus einzuführen, ohne damit einen nicht sterilen Gegenstand zu berühren", lässt sich in der von Heymann geschilderten Weise niemals erfüllen. Tch führte bei 12 Schwangeren die Bougie nach seiner Vorschrift in den Cervicalcanal, zog es zurück und tauchte es dann in Gelatine. In allen Fällen ging eine sehr grosse Anzahl von Colonien auf. Von Sterilität ist also keine Rede, kann auch keine Rede sein, da die Scheide von Bacterien wimmelt, und die zweite Prämisse der Methode, dass die Scheidenkeime nicht infectiös seien, wird bekanntlich auch nicht überall zugegeben.

Warum aber sollen wir es überhaupt darauf ankommen lassen, ob Scheiden- oder gar Introituskeime in Massen weit hinein in den Uterus gebracht, dort wirkungslos zu Grunde gehen? Diesem gewagten Spiele gehen wir am besten aus dem Wege, indem wir die Portio ins Speculum einstellen und so unter Leitung des Auges nach Auswischen der Cervix die Bougie einführen. So lässt sich das Einschleppen von Scheidenkeimen in den Uterus mit Sicherheit vermeiden. Keimfrei gelangt die Bougie allerdings nur selten in die Gebärmutter. Von 11 auf diese Weise in die Cervix eingeführten Bougies war nur eine steril, doch war die Zahl der

1) Centralbl. f. Gyn. 1897. No. 45. S. $1340,1345$.

2) Dieses Archiv. Bd, 59. S. 404 . 
Colonien bei den übrigen $10 \mathrm{im}$ Vergleich zu den Resultaten des Heymann'schen Verfahrens versehwindend klein. Auch halte ich diese ohne Zweifel aus dem Cervicalcanale stammenden Keime für harmloser als jene Bacterien, die man bei der Heymann'schen Nethode auf dem langen Wege vom Introitus an mitnimmt. Aus diesen Gründen glauben wir uns nicht berechtigt, das Speculum bei der Einführung einer Bougie zu vermeiden.

Wenn der Geburtshelfer nicht die Bacterien der äusseren Genitalien weiterschleppt, so können sie auch allein hinaufwandern ${ }^{1}$ ). So hält Bumm eine von aussen aufsteigende' Fäulniss für die Ursache der putriden Endometritis ${ }^{2}$ ).

In unserem Streben, den Einfluss inficirter Introitusverletzungen auf das Wochenbett auszuschalten, werden wir das Hauptgewicht auf die Prophylaxe zu legen haben. Hier kommen zwei Factoren zur Geltung: Desinfection des Geburtshelfers mit seinen Instrumenten etc. und Desinfection der Kreissenden.

Während man sich über die Desinfection der Hände im Princip (allerdings nicht in der Wahl der Methode) einig ist, sind, was die Desinfection der Kreissenden anbelangt, die Ansicbten noch sehr versehieden, ja der Streit der Scheidendesinfection hat die Zahl der Geburtshelfer in zwei Lager gespalten, die auch nach den eingehendsten bacteriologischen Arbeiten der Neuzeit immer noch nicht Frieden geschlossen haben. Uebereinstimmung herrscht bei der Mehrzahl der Autoren wohl nur darin, dass man bei operativen Geburten die Scheide ausspülen soll. Am weitesten geht Hofmeier ${ }^{3}$, der jeden Arzt, welcher vor operativen Geburten nicht gründlich die äusseren Genitalien und die Scheide desinficirt, für schuldig im Sinne $\$ 222$ des Strafgesetzbuches hält. Darauf erwidert $\mathrm{Kühn}^{4}$ ), unseres Erachtens mit Recht, dass dieses Verfahren noch nicht zu den allgemein anerkannten Regeln der ärztlichen Kunst geböre und ein Verstoss dagegen bis jetzt nicht strafbar sei. Ausserdem sind wir der Ansicht, dass die Infectionsgefahr bei operativen und spontanen Geburten ich möchte sagen nur quantitativ verschieden ist: allerdings ist sie bei operativen Ge-

1) Gebhard, Zeitschrift f. Geb. und Gyn. Bd. 37. Heft 1. S. 135. Schenk, Dieses Archiv. Bd. 55. S. 437.

2) Centralbl. für Gyn. 1899. No. 21. S. 629.

3) Münchener med. Wochenschr. 1899. No. 48. S. 1602.

4) Daselbst. 1899. No.51. S. 1724. - Vergl. auch Meyerson, Dieselbe Zeitschrift. 1900. No. 3 . 
burten grösser, aber alle Factoren spielen, wenn auch nicht so weitgehend, auch bei der normalen Geburt immerhin ihre Rolle im Kleinen ${ }^{1}$ ). Consequenterweise müssten wir also auch bei jeder Geburt die inneren Genitalien desinficiren. So sagt auch König ${ }^{2}$ ): "Wird die Asepsis des Geburtscanales der Kreissenden anerkannt, so können die Scheidenspülungen nicht blos bei den spontanen, sondern auch bei den operativen Geburten entbehrt werden."

Also entweder niemals ausspülen oder immer! In diesem Dilemma würden wir uns für Hofmeier's Standpunkt entscheiden, wenigstens soweit die Geburtshülfe in Anstalten in Frage kommt; ob man aber in der Praxis seinen Ansprüchen wird genügen können, erscheint uns fraglich ${ }^{3}$ ). Jedenfalls halten wir es für bedenklich, die Hebammen zur Scbeidendesinfection zu verpflichten, möchten es auch bezweifeln, dass die Mehrzahl derselben den Cervicalcanal desinficiren kann, da in vielen Fällen ihre Finger zu kurz sind.

Anders liegt die Sache mit der Desinfection der äusseren Genitalien der Kreissenden. Hier geht die Einigkeit der Geburtshelfer wenigstens soweit, dass allgemein mindestens eine gründliche Säuberung mit Wasser und Seife verlangt wird. Mermann ${ }^{4}$ ) allerdings lässt die äusseren Genitalien im Bade mit Watte nur abwischen, dagegen die Hände der Kreissenden in der gründlichsten Weise desinficiren. Meiner Ansicht nach sollte der Angriffspunkt für unsere Prophylaxe näher an den Genitalien liegen; dass die Kreissende sich mit den eigenen Händen inficirt, können wir leicht verhindern.

Eine Reihe von Geburtshelfern begnügt sich mit einer gründlichen Waschung der äusseren Genitalien, und auch das preussische Hebammenlehrbuch (\$71) verlangt keine Desinfection der Theile, sondern nur ein Waschen mit reinem, womöglich durchgekochtem Wasser. Gegen die eindringliche Vorschrift einer peinlichen Händedesinfection, wie sie dasselbe Buch verlangt, klingt diese Forderung sehr bescheiden und fraglos wird sie von den Hebammen meist nicht mit der genügenden Gründlichkeit befolgt.

1) Bumm, Dieses Archiv. Bd. 34. S. 355 .

2) Münchener med. Wochenschr. 1900. No. 1. S. 4.

3) Fehling, Dieses Archiv. Bd. 35. S. 495. - Steffeck, ebenda S. 501. - Mermann, Centralbl. f. Gyn. 1887. S. 539. - Szabó, Dieses Archiv. Bd. 36. S. 176.

4) Centralbl. f. Gyn. 1889. No. 16. S. 272 . 
Wir haben aber nach unseren obigen Ausführungen allen Grund, eine genaue Desinfection der äusseren Geschlechtstheile zu verlangen ${ }^{1}$, denn eine einfache Waschung mit Seife und Wasser ist und bleibt immer nur eine halbe Maassregel, die Baumm²) allerdings für genügend hält. Während man den Hebammen nicht für jede Geburt die Scheidenausspülung zur Pflicht machen darf, sehen wir keinen Grund, der die obligatorische Einführung einer Desinfection der äusseren Genitalien verbieten könnte. Schreibt doch auch das sächsische Hebammenlehrbuch (6. Aufl. 1897. S. 63) vor, dass die Hebamme die äusseren Geschlechtstheile der Kreissenden 5 Minuten waschen und dann mit 3 proc. Carbolsäure 3 Minuten lang desinficiren soll. Man vergleiche mit dieser präcisen Instruction, die eine Desinfection der Kreissenden der der eigenen Hände völlig gleichstellt, die entsprechende Vorschrift des preussischen Hebammenlehrbuches!

Mag man nun die äusseren Genitalien der Kreissenden desinficiren oder waschen, beides bleibt unvollkommen, wenn uns die Haut nicht genügend zugänglich ist, wenn die langen Haare uns hindern. Welcher Chirurge würde wohl auf der behaarten Kopfhaut operiren ohne vorher zu rasiren? Dem Geburtshelfer sind die Haare der äusseren Genitalien bei der Desinfection ebenso hinderlich, ja sie sind hier besonders gefährlich, da sie als Infectionsträger vom touchirenden Finger weit in die Vagina hineingeschleppt werden können. Wir möchten nun allerdings nicht der Hebamme das Rasirmesser anvertrauen, wohl aber ihr vorschreiben (was bisher in Preussen nicht der Fall ist), dass sie die Schamhaare jeder Kreissenden soweit wie irgend möglich mit der Scheere kürzen soll. $D a$ die Nabelschnurscheere wegen ihrer Form wie aus Gründen der Asepsis hierzu nicht geeignet schien, warde in der hiesigen Anstalt eine Scheere verwandt, die durch ihre Flächenkrümmung ein Kürzen der Haare bis auf wenige Millimeter gestattet ${ }^{3}$ ). Ihre Handhabung ist einfach, und sie wurde von Hebammenschülerinnen und alten, zum Wiederholungskurse einberufenen Hebammen lieber gebraucht als eine gewöhnliche Scheere ohne Krümmung. Wir können

1) Spencer, British Med. Journal. 1899, 14. October. S. 966 . Szabó, zweite Arbeit. S. 187.

2) Dieses Archiv. Bd. 52. S. 624.

3) Sie wird rom Messerschmied Hensel, Osnabrück, Grosse Strasse, hergestellt. Preis bei Abnahme eines Dutzend 1,25 Mk. pro Stück. 
also nur empfehlen, diese oder eine ähnliche Scheere für Hebammen einzuführen. Sie würde zugleich auch zum Schneiden der Fingernägel recht gut verwandt werden können.

Nachdem die Haare gründlich gekürzt sind, sollen die Theile mit Wasser und Seife 5 Minuten lang energisch gewaschen und dann 3 Minuten mit 3 proc. Carbollösung desinficirt werden. Diese genaue Vorschrift des sächsischen Hebammenlehrbuches sollte auch in das preussische aufgenommen werden, denn die Hebamme braucht derartige präcise, schematische Vorschriften, da sie wohl nur selten nach eigenem Denken zu handeln im Stande sein dürfte. Allerdings können wir nicht annehmen, dass durch dieses exacte Verfahren die äusseren Genitalien keimfrei gemacht werden könnten. Doch liegt dies nicht an der Wahl des Desinficiens. Ich versuchte bei Schwangeren 3 proc. Carbolsäure, Liq. Cresoli sapon. (Ahlfeld) und Spiritus sapon. nach Mikulicz ${ }^{1}$ ). Nach wenigen Versuchen, in denen das bacteriologische Resultat allerdings ganz günstig scbien, sahen wir aber von weiterer Verwendung des Spir. sapon. ab, da die Schwangeren stets über heftiges Brennen klagten, was bei Controlversuchen mit Carbol und Cresol nicht der Fall war.

Die Resultate, die wir mit dem von Ahlfeld (Lehrb.) empfohlenen Liq. Cresoli sapon. und der Carbolsäure erhielten, waren die gleichen: Keimfreiheit liess sich in keinem Falle erzielen. Darüber kann man sich nicht wundern, da es auch nur in den seltensten Fällen gelingt, unsere eigenen Hände zu sterilisiren ${ }^{2}$ ).

Trotzdem wird aber Niemand eine einfache Waschung der Hände einer exacten Desinfection derselben gleichwerthig erachten, und wenn wir - diesen Findruck haben wir bei unseren Versuchen gewonnen - die Keime der äusseren Genitalien zwar nicht sämmtlich entfernen, aber doch erheblich vermindern können, so ist der Vortheil der Methode damit bewiesen. Ein bestimmtes Desinficiens möchte ich nicht empfehlen; doch dürfte es aus praktischen Gründen gerathen sein, für Hebammen zur Desinfection: der äusseren Genitalien das gleiche Mittel vorzuschreiben, wie für die der Hände, am besten wohl das einmal eingeführte Carbol oder Lysol.

Da die Erfahrung lehrt, dass auch die Schleimhaut der

1) Deutsche med. Wochensehr. 1899. No. 24.

2) Paul und Sarwey, Münchener med. Wochenschrift. 1899. No. 51. S. 1727 . 
kleinen Labien p. part. häufig Risse aufweist, die später den Boden für ein Ulcus abgeben, so sollte die Hebamme die kleinen Labien auseinanderziehen und die Schleimhaut, soweit sie dem Auge zugängig ist, schonend desinficiren.

Im weiteren Verlaufe der Geburt soll die sächsische Hebamme alle 2--3 Stunden die äusseren Genitalien mit Carbol abspülen. Wir können auch dieser Forderung nur beistimmen; denn, was man durch die erste Desinfection erreichte, wird im Laufe der Geburt durch die unvermeidliche Berührung der Theile mit allen möglichen Dingen immer wieder illusorisch gemacht.

Mit diesen Vorschriften des sächsischen Hebammenlehrbuches, deren volle Berechtigung wir im Vorhergehenden genügend nachgewiesen zu haben glauben, sind aber die Prophylaxe und die Massnahmen gegen eine spätere Infection der Introituswunden noch nicht erschöpft. Vielmehr erscheint es uns genau so wichtig, dieser Gefahr auch im Wochenbette mit der gleichen Vorsicht zu begegnen. Allerdings ist die Aufgabe recht schwer zu lösen, denn das bei den gegebenen ungünstigen Verhältnissen allein mögliche Verfahren der offenen Wundbehandlung stösst hier auf erhebliche Schwierigkeiten. Gerade der ersten Forderung einer offenen Wundbehandlung können wir nur schwer in vollem Umfange gerecht werden: wie wollen wir eine Stagnation der keimhaltigen Sekrete verhüten?

Häufige Abspülungen der äusseren Genitalien sind zu diesem Zwecke gewiss recht nützlich. Statt des abgekochten Wassers, wie es das sächsische und preussische Hebammenlehrbuch verlangen, wäre eine $1 / 2$ proc. Lysollösung vielleicht geeigneter aus Gründen der Antiseptik. Wichtiger ist die Frage nach der Mäufigkeit der Spülungen. Die preussische Hebamme soll in den ersten Tagen des. Wochenbettes die äusseren Genitalien 3--4 mal täglich abspülen, für die sächsische ist nur 2 mal täglich bis zum 9. Tage des Wochenbettes vorgeschrieben. Wenngleich wir aus theoretischen Gründen häufigeren Spülungen den Vorzug geben und sie für Anstalten mit genügendem Personal sowie für wohlhabende Kreise, denen eine eigene Wochenbettspflegerin zur Verfügung steht, entschieden billigen, lehrt uns die Praxis, dass die Hebamme, und zwar besonders die auf dem Lande, ihre Wöchnerinnen nur selten 3-4mal am Tage besuchen, ja sie oft tagelang nicht sehen. Uns erscheint daher die sächsische, übrigens auch präciser gefasste Vorschrift (\$ 153) einer 2 maligen Abspülung der Praxis ange- 
messener, zumal auch das preussisehe Lehrbuch hervorhebt, dass eine 3-4 malige Abspülung nicht immer von der Hebamme besorgt werden könne.

Ferner ist die sächsische Hebamme (\$ 153) verpflichtet, bei Oedem der Labien einen Arzt rufen zu lassen, eine Vorsichtsmassregel, die beweist, dass man sich dort in der ernsteren Beurtheilung der Introituswunden unserem Standpunkte nähert. Wir sahen z. B. bei einer Nichtuntersuchten am 2. Tage des Wochenbettes ein ausgedehntes Oedem der äusseren Genitalien auftreten. Deshalb können wir nur rathen, die Bestimmung des sächsischen Lehrbuches auch für Preussen zu treffen.

Wir haben oben als leitenden Grundsatz ausgesprochen, dass wir im Wochenbette eine Stagnation der Lochien verhüten sollen. Mit dieser doch wohl allerseits anerkannten Forderung setzt sich unseres Erachtens das preussische Hebammenlehrbuch in Widerspruch, wenn es vorschreibt, die Hebamme solle einen reinen Wattebausch vor die Genitalien der Wöchnerin legen (\$ 160). Mehr befriedigt uns schon das sächsische Lehrbuch; dieses bestimmt ein in 3 proc. Carbollösung ausgerungenes Stopftuch, gestattet leider aber auch die Benutzung keimfreier Watte. Letztere dürfte den Hebammen in der Praxis wohl nur selten zur Verfügung gestellt werden; im Gegentheil, die Watte, die tagelang in einem Schranke, Kasten etc. neben allen möglichen täglich benutzten Gegenständen lag, sieht für ein bakteriologisches Auge oft recht verdächtig aus. Da können wir, soweit die Aseptik in Frage kommt, zu einem frischgewaschenen Stopftuche mindestens das gleiche Vertrauen haben.

Den eigentlichen Zweck aber, die Lochien möglichst vollständig aufzusaugen, erfüllt das Stopftuch weit besser als Watte. Ein Wattebausch, der mehrere Stunden vor den Genitalien der Wöchnerin gelegen hat, hat sich nur in den dem Strome der Lochien unmittelbar ausgesetzten Partien vollgesogen, hier aber ad maximum, so dass meist auf der Oberfläche noch mehr oder weniger Secret stagnirt, anstatt dass durch Weiterleitung in die fernere Umgebung die imbibirten Partien entlastet würden. So aber gleicht der Effect vielleicht mehr einer Behinderung des Abflusses als einer Förderung, ja wir glauben, dass ein dicht vor den Genitalien liegender, durch die festgeschlossenen Schenkel gehaltener Wattebausch leicht zur Entstehung von Lochiokolpos Anlass geben kann. 
Wir verwerfen deshalb die Watte entschieden und möchten an ihre Stelle ein sauber gewaschenes Stopftuch setzen, welches ein weit höheres Aufsaugungsvermögen entwickelt. Man lege unter die Genitalien zuerst einen grossen Wattebausch und unter diesen wieder ein Stopftuch; nach einigen Stunden hat sich das letztere in bedeutend weiterem Umfange vollgesogen als die Watte, über den peripheren, durchtränkten Theilen des Stopftuches liegt völlig trockne Watte. Dass hierbei nicht die Schwerkraft das wesentliche Moment ist, das die Imbibition des tiefer liegenden Stopftuches begünstigt, zeigt sich bei umgekehrter Anordnung des Versuches: das Resultat ist dasselbe, auch wenn das Stopftuch über der Watte liegt.

Alle diese Gründe beweisen wohl zur Genüge, dass der Watte nicht der Platz gebührt, der ihr bislang in der Wochenbettsbehandlung eingeräumt ist. Auch in der Chirurgie sind ihrer Verwendung bestimmte Grenzen gezogen, und kein Chirurge würde eine stark secernirende Wunde mit Watte unmittelbar bedecken oder gar Abscesshöhlen damit tamponiren. Hat etwa der Geburtshelfer, für den doch die Gesetze der Chirurgie gelten wie für jeden Arzt, das Recht, gegen die erste Forderung, ja gerade gegen das Princip der offenen Wundbehandlung zu verstossen?

Jch glaube sagen zu können, dass die fiebernden Wöchnerinnen in unserer Anstalt seltener geworden sind, seitdem nach allen diesen Grundsätzen verfahren wurde, und möchte dringend zur Nachprüfung derselben auffordern. Absichtlich habe ich es vermieden, unsere Ansichten mit Zahlen zu belegen; sie hätten doch nur beschränkten Werth, da mit der Einführung unserer Methode zugleich auch das gesammte Personal der Anstalt wechselte.

In einer späteren Arbeit gedenken wir über Versuche zur bakteriologischen Differenzirung der auf den puerperalen Wunden der äusseren Genitalien liegenden Keime zu berichten.

Zum Schlusse erübrigt mir noch die angenehme Pflicht, meinem verehrten Chef, Herrn Director Dr. Rissmann, für seine ständige Berathung und Unterstützung bei dieser Arbeit verbindlichst $\mathrm{zu}$ danken. 